\title{
Access of surface meltwater to beds of sub-freezing glaciers: preliminary insights
}

\author{
Richard B. ALLEY, Todd K. DUPONT, Byron R. PARIZEK, Sridhar ANANDAKRISHNAN \\ Department of Geosciences and EMS EESI, The Pennsylvania State University, University Park, PA 16802-7501, USA \\ E-mail: ralley@essc.psu.edu
}

\begin{abstract}
Sufficiently deep water-filled fractures can penetrate even cold ice-sheet ice, but glaciogenic stresses are typically smaller than needed to propagate water-filled fractures that are less than a few tens of meters deep, as shown by our simplified analytical treatment based on analogous models of magmatic processes. However, water-filled fractures are inferred to reach the bed of Greenland through $>1 \mathrm{~km}$ of ice and then collapse to form moulins, which are observed. Supraglacial lakes appear especially important among possible crack 'nucleation' mechanisms, because lakes can warm ice, supply water, and increase the pressure driving water flow and ice cracking.
\end{abstract}

\section{NOTATION}

All physical values are from Hooke (1998) unless otherwise noted.

C Ice heat capacity $\left(2093 \mathrm{~J} \mathrm{~kg}^{-1} \mathrm{~K}^{-1}\right)$

d Crack depth $(\mathrm{m})$

$g \quad$ Gravitational acceleration $\left(9.8 \mathrm{~m} \mathrm{~s}^{-2}\right)$

$G \quad$ Potential gradient driving water flow $\left(\mathrm{Pa} \mathrm{m}^{-1}\right)$

$L \quad$ Ice latent heat of fusion $\left(3.3 \times 10^{5} \mathrm{~J} \mathrm{~kg}^{-1}\right)$

$K_{\mathrm{l}} \quad$ Opening-mode stress intensity factor $\left(\mathrm{Pa} \mathrm{m}^{1 / 2}\right.$ )

$K_{\text {lc }} \quad$ Opening-mode fracture toughness of ice $\left((1-4) \times 10^{5} \mathrm{~Pa} \mathrm{~m}^{1 / 2}\right)($ Van der Veen, 1998a)

$M \quad$ Elastic stiffness $\left(5 \times 10^{9} \mathrm{~Pa}\right)$

$P \quad$ Hydrostatic crack pressure $(\mathrm{Pa})$

$P_{\mathrm{ct}} \quad$ Crack-tip stress drop $(\mathrm{Pa})$

$t \quad$ Time $(\mathrm{s})$

$t_{\mathrm{f}} \quad$ Time since fracture tip passed (s)

$T_{\mathrm{b}} \quad$ Melt temperature and freezing temperature (K)

$T_{0} \quad$ Initial ice temperature (K)

$u \quad$ Velocity of fracture tip $\left(\mathrm{m} \mathrm{s}^{-1}\right)$

$\checkmark \quad$ Crack volume per unit width $\left(\mathrm{m}^{2}\right)$

$w \quad$ Crack width in $y$ direction $(\mathrm{m})$

$x \quad$ Vertical coordinate

y Horizontal coordinate across crack

$z \quad$ Horizontal coordinate along crack

$\delta \quad$ Thickness of frozen-on layer $(\mathrm{m})$

$\Delta P \quad$ Internal crack pressure $(\mathrm{Pa})$

$\Delta \rho \quad \rho_{\text {water }}-\rho_{\text {ice }}\left(90 \mathrm{~kg} \mathrm{~m}^{-3}\right)$

$\eta \quad$ Water viscosity $\left(1.8 \times 10^{-3}\right.$ Pa s) (Weertman, 1972)

$\kappa \quad$ Thermal diffusivity of ice $\left(1.18 \times 10^{-6} \mathrm{~m}^{2} \mathrm{~s}^{-1}\right)$

$\lambda \quad$ Thermal scale

$\mu \quad$ Elastic shear modulus $\left(3.8 \times 10^{9} \mathrm{~Pa}\right)$

$\nu \quad$ Poisson's ratio $(0.31)$

$\rho_{\text {ice }} \quad$ Ice density $\left(910 \mathrm{~kg} \mathrm{~m}^{-3}\right)$

$\rho_{\text {water }}$ Water density $\left(1000 \mathrm{~kg} \mathrm{~m}^{-3}\right)$

$\sigma_{y}^{\prime} \quad y$-directed deviatoric stress $(\mathrm{Pa})$

$\sigma_{y_{\min }}^{\prime} \quad$ Minimum $y$-directed deviatoric stress to drive $\operatorname{crack}(\mathrm{Pa})$

\section{INTRODUCTION}

Clean surface meltwater flows into moulins on the surface of low-elevation parts of the Greenland ice sheet, but debrisbearing streams emerge from beneath the ice in places. Onset of summertime meltwater drainage causes ice-flow speed-up, with warmer years experiencing more speed-up (Zwally and others, 2002). This evidence suggests that surface meltwater thus reaches the bed, despite the necessity of penetrating $>1 \mathrm{~km}$ of sub-freezing ice in some places.

If the observations of Zwally and others (2002) from one site near the equilibrium line on the west side of the ice sheet are broadly applicable, then future warming would be expected to increase flow velocities, drawing down the ice sheet and increasing sea-level rise. Indeed, inclusion of this effect in a numerical model of the ice sheet moderately increases the rate of future ice-sheet drawdown and sealevel rise in comparison to model runs lacking the enhanced lubrication by surface meltwater (Parizek and Alley, 2004).

The increase in sea-level rise from this effect depends on several factors, as described by Parizek and Alley (2004). Prominent among these is whether water access to the bed will migrate inland in response to warming and inland migration of the zone producing surface meltwater runoff. Because we lack a clear process-level understanding of the way(s) that surface meltwater reaches the bed, we cannot now project future behavior with confidence.

In this short contribution, we review the situation, sketch a possible solution path and identify additional work required. We find that 'nucleation' of throughgoing cracks that serve as precursors to moulins is difficult in cold ice, but that once nucleated, propagation to the bed followed by crack collapse to channels is expected if sufficient water is supplied. Of the possible mechanisms for overcoming the nucleation barrier, supraglacial lakes are especially interesting, as suggested by Scambos and others (2000) for ice-shelf break-up and by Boon and Sharp (2003) for meltwater drainage through an arctic glacier. Conditions sufficient for formation of supraglacial lakes can be estimated (Dupont and Alley, 2005; Alley and others, in press), and we are pursuing this line of inquiry.

\section{CRACK PROPAGATION}

Ice flow transports cold ice from the accumulation zone of Greenland into the ablation zone, where sub-freezing 
temperatures can exist a few meters below the surface (and seasonally to the surface) and can extend to or near the bed through hundreds of meters to $>1 \mathrm{~km}$ of ice. There exists no plausible mechanism for a stream of meltwater on the surface to directly 'drill', mill or melt a hole through such ice, yet holes or moulins observed on the surface presumably deliver surface meltwater to the ice-sheet bed (Zwally and others, 2002). The likely mechanism consists first of propagation of a water-filled fracture through the ice (Fountain and others, 2005), followed by localization of flow through the 'Walder instability' (Walder, 1982) in which the enhanced thermal dissipation in thicker regions causes enhanced melting and pressure drop leading to channel formation.

Crack formation and propagation require that three thresholds be exceeded. First, the local tensile stress from ice flow or thermal contraction must exceed the critical stress intensity at the tip of a 'pre-crack' (flaw in the ice), allowing propagation. Existence of crevasses demonstrates that this criterion is at least occasionally exceeded. This condition for temperate ice has been considered extensively in the literature (e.g. Weertman, 1973; Van der Veen, 1998a, b), and sophisticated calculations have been made including such factors as depth variation of density, lateral variation in crevasse spacing, variation in water fill, and the effects on fracture propagation of the finite thickness of a glacier vs the infinite half-space often assumed in analyses. We focus primarily on the difficulty introduced by the subfreezing nature of some ice, and so take the simplest physical treatment of this first criterion.

Once propagation is initiated, we consider two criteria for continuation. Weertman (1973), Van der Veen (1998b) and Scambos and others (2000) showed that glacial deviatoric stresses are insufficient to overcome hydrostatic stresses and continue propagation to great depth unless a crack remains (nearly) water-filled. Lack of filling to the surface may allow freezing to plug the crack from above, or a water-filled region may 'pinch off' from the crack and propagate away (Weertman, 1973; Rubin, 1995; Fountain and others, 2005); in either case, continuous connected water from surface to bed to enable moulin formation would be lost.

Provided a crack remains water-filled and with high enough stress, propagation through cold ice also requires that water influx to the growing crack exceeds water freezing from energy loss into the cold ice. If this criterion is not satisfied, a crack will freeze up, producing one of the 'blue bands' that are so commonly observed in ablation zones and icebergs. Sufficiently high stresses with sufficiently rapid water influx will allow water-filled cracks to propagate.

\section{PHYSICAL SOLUTION}

Our solution largely follows the treatment of Rubin (1995) for propagation of magma-filled cracks through brittle crustal rocks. We wish to estimate whether a water-filled crack can penetrate through hundreds of meters of subfreezing ice to the bed under expected glaciogenic stresses. Magma propagation often is driven by an overpressurized magma chamber, and basal crevassing may involve such overpressure (Van der Veen, 1998a; Roberts and others, 2000; Ensminger and others, 2001). We will argue below that such overpressure from supraglacial lakes may be

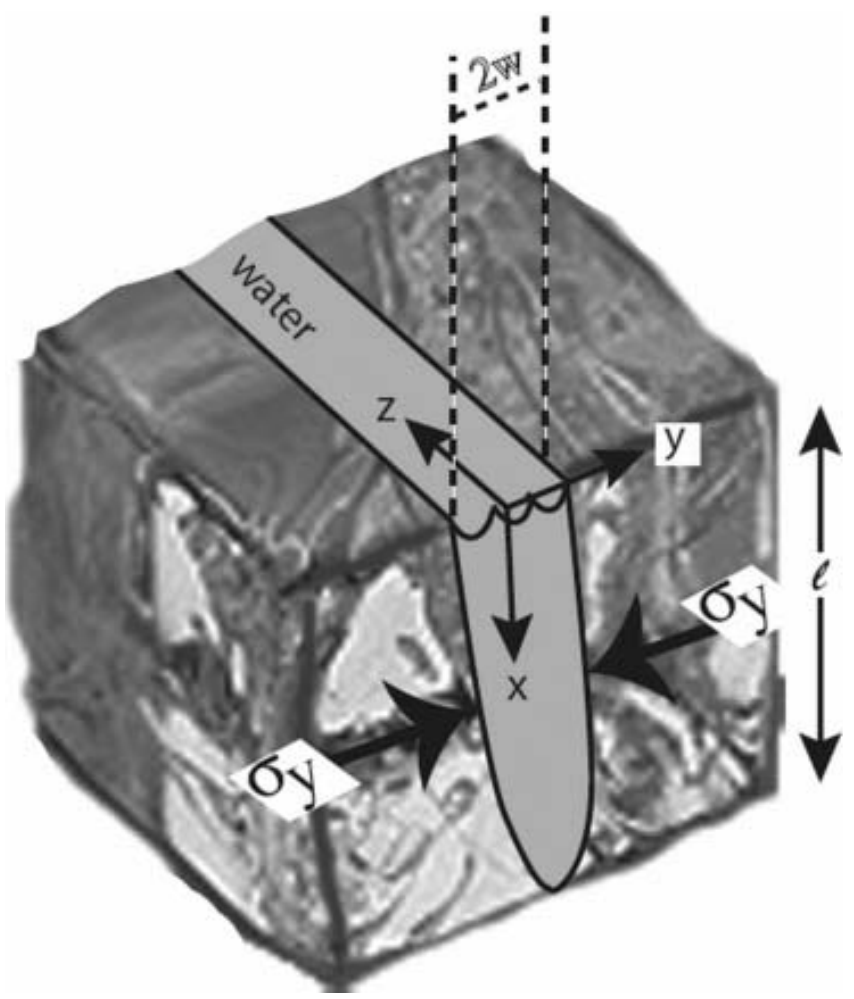

Fig. 1. Coordinate system used. The longitudinal deviatoric crackopening stress is indicated by $\sigma_{y}$.

important in downward propagation of cracks through Greenland ice, but we start by assuming that no lake exists and showing the difficulties that then result. Note that the case of propagation of an initially short crack without an overpressurized reservoir is not considered extensively by Rubin (1995), but we are able to borrow many related results. The interested reader is referred to Rubin (1995), who provides further referencing and much greater insight into the fascinating suite of problems posed by magma-filled cracks.

We consider the situation shown in Figure 1, with a crack extending downward for a distance $d$ along the $x$ axis from the origin at the surface of the ice sheet, extending infinitely in length along the horizontal $z$ direction, and opening $2 w(x=0)$ along the horizontal $y$ axis in response to an internal pressure, $\Delta P(x)$, given by

$$
\Delta P(x)=P(x)-\sigma_{y}^{\prime}(x)-P_{\mathrm{ct}}
$$

with $P_{\mathrm{ct}}$ a dynamic drop in water pressure associated with crack propagation. Note that the far-field deviatoric stress $\sigma_{y}^{\prime}$ here is negative if tensile, and that we are taking the simplest situation of a single horizontal tension. The pressure $P(x)$ is the difference between the fluid pressure in the crack, which we assume to be water-filled, and the hydrostatic pressure in the ice, which we take for simplicity as the weight of the overburden; hence

$$
P(x)=\Delta \rho g x,
$$

where $\Delta \rho=\rho_{\text {water }}-\rho_{\text {ice, }}$ with $\rho$ denoting density. The additional term $P_{\mathrm{ct}}$, denoting dynamic drop in water pressure associated with crack propagation, will be discussed below; it also is a function of $x$, but primarily matters very close to the crack tip. 
The half-width of the crack, $w$, at $x=0$ is approximated by (Rubin, 1995, equation (1))

$$
w(x=0)=\frac{\Delta P}{M} d,
$$

where the elastic stiffness

$$
M=\frac{\mu}{1-\nu}
$$

with $\mu$ the elastic shear modulus and $\nu$ Poisson's ratio.

We follow Rubin (1995) in taking the stress intensity factor $K_{l}$ for crack propagation assuming linear elastic fracture mechanics as approximately

$$
K_{\mathrm{I}}=\Delta P \sqrt{d} .
$$

We note that the crack cannot be infinite in length in the horizontal $\mathrm{z}$ direction, as is assumed here, but that calculations for a more realistic penny-shaped crack would change our results only slightly; $K_{\mathrm{I}}$ for a penny-shaped edge crack is a weak function of orientation but is typically only about 20\% larger than given in Equation (5) (Smith and others, 1967), a sufficiently small difference that we do not consider it further. (Other shape factors than for a pennyshaped crack also could be considered, but similarly produce multiplicative factors of order one.) We also note that $P$ in Equation (1) increases slowly and linearly from zero at the surface to only about $10^{5} \mathrm{~Pa}=1$ bar at $110 \mathrm{~m}$; in comparison, because crevasse formation is localized on glaciers and ice sheets, we expect regions of crevasse formation to typically have $\sigma_{y}^{\prime}$ in excess of usual values of glacial stresses and thus in excess of $\approx 1$ bar. We follow Rubin (1995) in considering a shallow region in which the buoyancy term $P(x)$ can be neglected, and a deep region in which this buoyancy term is dominant, with the changeover in the neighborhood of $d=100 \mathrm{~m}$ or more.

The simplest criterion for fracture propagation is that $K_{\mathrm{l}}$ in Equation (5) exceed the fracture toughness $K_{\mathrm{lc}}$. If this is satisfied and the crack is propagating, then the volume of the crack will be increasing in the absence of freezing. Approximating the crack as a rectangular parallelopiped, of width $2 w(0)$ from Equation (3) and depth $d$, yields the volume $V$ per unit length in the $z$ direction

$$
V=2 w d \text {. }
$$

(We have looked at using more realistic geometry, and especially an elliptical shape, but the small geometrical improvement seems to make little difference in the results, while complicating those results.) In the shallow region with the crack-opening deviatoric stress dominant in Equation (1), the rate of volume increase for a crack deepening at rate $u=\partial d / \partial t$ is

$$
\left(\frac{\partial V}{\partial t}\right)_{\text {opening }}=-\frac{4 \sigma_{y}^{\prime} d u}{M}
$$

with $\sigma_{y}^{\prime}$ still being taken as a constant.

The thermal problem is quite complex, with development of boundary layers in fluid and solid. For meltwater at its unique freezing temperature $T_{\mathrm{m}}$ and ice at initial temperature $T_{0}$, the thickness of the frozen-on layer, $\delta(x)$, during the initial stages of fracture propagation is approximately (Rubin, 1995)

$$
\delta(x)=2 \lambda \sqrt{\kappa t_{f}}
$$

with

$$
\lambda=\frac{C\left(T_{\mathrm{m}}-T_{0}\right)}{\sqrt{\pi} L}
$$

and with $\kappa$ the thermal diffusivity, $C$ the specific heat and $L$ the latent heat of ice, and $t_{f}$ the time since the freezing started at position $x$. If we make the simplifying assumption that $u$ is constant during growth of a crack (an assumption that probably is too restrictive, and that should be relaxed in future work), then the total rate of freezing in a crack of depth $d$ can be estimated by taking the time rate of change of $\delta$ in Equation (8) and integrating from the surface to $d$ assuming that freezing begins at the moment the crack opens, yielding

$$
\left(\frac{\partial V}{\partial t}\right)_{\text {freezing }}=-2 \lambda \sqrt{\kappa u d}
$$

For the crack to propagate to great depth, it must remain connected to a supply of meltwater, which we take to exist at the surface, so we require that the crack remain waterfilled to the surface. Propagation requires meltwater inflow to offset the freezing and to fill new crack space; hence, there must be a potential drop along the crack in the $x$ direction. Crack propagation also creates an underpressure in the tip of the crack, which may actually become vaporfilled rather than water-filled, as the crack tip propagates away from the water source (Rubin, 1995). Most of the potential drop along a crack is very close to the crack tip, owing to the cubic dependence of laminar fluid flow on crack aperture, as described below.

For want of a better approach, we make two simplifying assumptions to assess the water inflow. First, we assume that the water flows in through thickness $2 w$ rather than through the reduced thickness $2 w-2 \delta$. Next, we assume that the potential drop driving flow is uniformly distributed along the crack rather than concentrated at the tip. Again, these assumptions point in the direction of future work and are discussed further below. Both lead to overestimates of crack growth compared to crack freeze-up by providing a larger potential gradient and a wider aperture at the water inlet than likely, hence supplying more water than is likely in reality, and so our modeled cracks will propagate more easily than will actual cracks; we crudely estimate associated errors below.

Finally, we require that the pressure drop at the crack tip, $P_{\text {ct, }}$, be such as to make $K_{\mathrm{l}}=K_{\mathrm{lc}}$ exactly; that is, we assume that the crack is propagating as rapidly as it can. Rapid propagation favors opening over freezing, and so is most favorable to crack growth. From Equations (1) and (5) with the crack-opening stress primarily provided by the ice-flow deviatoric stress,

$$
P_{\mathrm{ct}}=-\sigma_{y}^{\prime}-\frac{K_{\mathrm{lc}}}{\sqrt{d}}
$$

However, propagation cannot proceed faster than fluid inflow. Fluid inflow in turn provides $Q$ per unit length, given for laminar flow between parallel plates (e.g. Rubin, 1995, equation (3)) by

$$
Q=\frac{G(2 w)^{3}}{12 \eta},
$$

with $\eta$ the viscosity of water and

$$
G=\frac{P_{\mathrm{ct}}}{d}
$$

the magnitude of the potential gradient driving water flow. Again, the reader is reminded that we are working in the shallow-crack field where the far-field tensile stress is primarily responsible for crack opening. 
Equating Equations (7) and (10) and solving for $u$ provides the propagation velocity at which enlargement of the crack equals the freezing rate,

$$
u=\left(\frac{\lambda M}{-2 \sigma_{y}^{\prime}}\right)^{2} \frac{\kappa}{d}
$$

Then, estimating the crack-deepening velocity so that fluid inflow is just sufficient to fill the space created by the crack opening, with Equation (7) giving the opening rate and Equation (12) the flow filling it, and again solving for velocity,

$$
u=-\frac{G(2 w)^{3} M}{48 \sigma_{y}^{\prime} d \eta} .
$$

Taking $w$ from Equation (3) with $\Delta P \approx-\sigma_{y}^{\prime}(x)$, and $G$ from Equations (13) and (11) with $P_{\mathrm{ct}}>0$, hence $-\sigma_{y}^{\prime}>K_{\mathrm{lc}} / \sqrt{d}$ so the crack is propagating (and recalling that a tensile crack-opening stress has $\sigma_{y}^{\prime}<0$ here), Equation (15) becomes

$$
u=\sigma_{y}^{\prime 2}\left(-\sigma_{y}^{\prime}-\frac{K_{\mathrm{lc}}}{\sqrt{d}}\right) \frac{d}{6 \eta M^{2}} .
$$

For specified depth $d$, Equation (16) defines a curve $u\left(-\sigma_{y}^{\prime}\right)$ as shown in Figure 2. For larger stress magnitude, the crack is wide enough that water inflow can match volume increase from crack opening, maintaining the water-filled condition needed for meltwater access to the bed. Equation (14) also defines a curve, shown schematically in Figure 2, and stress magnitudes higher than on this curve allow volume creation by crack opening to exceed volume loss by freezing. Because these curves intersect and each defines a minimum stress magnitude for water-filled crack propagation to the bed, their intersection defines a minimum stress magnitude, $-\sigma_{y_{\min }}^{\prime}$ necessary for propagation.

Equating Equations (14) and (16) to eliminate $u$ and solving for this stress of minimum magnitude needed for crack propagation, $\sigma_{y_{\min }}^{\prime}$, we obtain

$$
\sigma_{y_{\min }^{\prime 4}}^{4}\left(-\sigma_{y_{\min }^{\prime}}^{\prime}-\frac{K_{\mathrm{lc}}}{\sqrt{d}}\right)-\frac{3 M^{4} \kappa \eta \lambda^{2}}{2 d^{2}}=0 .
$$

Substituting physical constants from the Notation section,

$$
\sigma_{y_{\min }}^{\prime 4}\left(-\sigma_{y_{\min }}^{\prime}-1.5 \times \frac{10^{5}}{\sqrt{d}}\right)=-\frac{2.7 \times 10^{27}}{d^{2}} .
$$

For $d=1 \mathrm{~m}, \sigma_{y_{\min }}^{\prime} \approx-3 \times 10^{5}$ Pa or tension of about 3 bar. For $d=10 \mathrm{~m}, \sigma_{y_{\min }}^{\prime} \approx-1.4 \times 10^{5} \mathrm{~Pa}$ or about $1.4 \mathrm{bar}$. For $d=100 \mathrm{~m}, \sigma_{y_{\min }}^{\prime} \approx-5 \times 10^{4} \mathrm{~Pa}$ or about 0.5 bar. However, at $d=100 \mathrm{~m}$, the driving stress from the pressure of the water would be significant, and the magnitude of $\sigma_{y_{\min }}^{\prime}$ would be correspondingly smaller.

The value of the fracture toughness we have used, from Fischer and others (1995), falls near the lower end of the range $(1-4) \times 10^{5} \mathrm{~Pa} \mathrm{~m}^{1 / 2}$ recommended by Van der Veen (1998b). The calculations are weakly sensitive to this value, with the stress for $d=10 \mathrm{~m}$ ranging from 1.3 to 1.7 bar for the range of fracture toughnesses $(1-4) \times 10^{5} \mathrm{~Pa} \mathrm{~m}^{1 / 2}$.

\section{DISCUSSION}

Given the number of assumptions involved, we do not place great faith in the numerical results. The general trend,

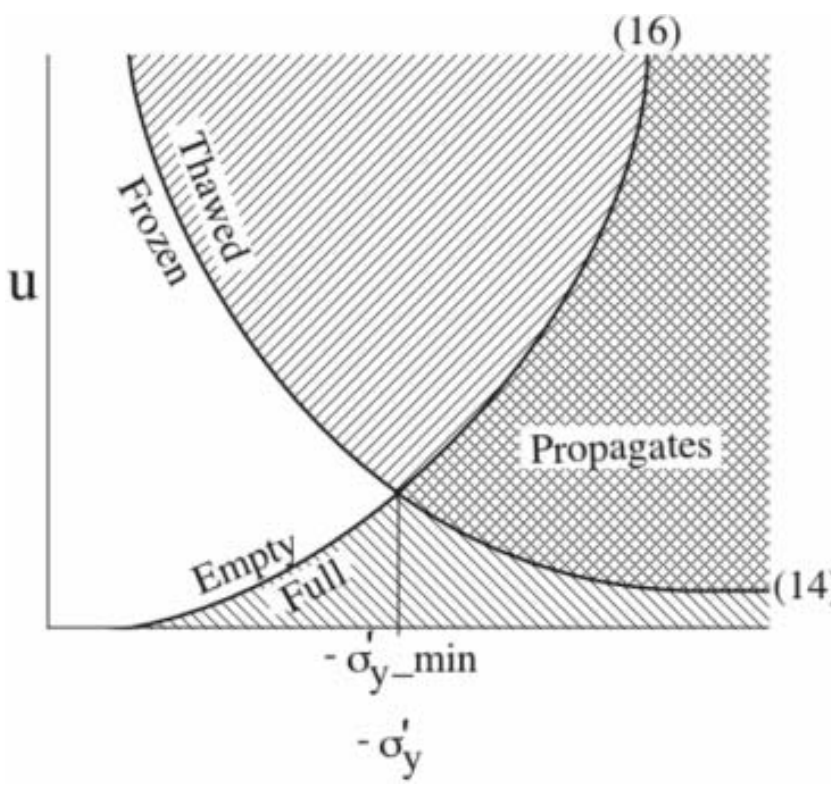

Fig. 2. Cartoon of solution space of crack propagation velocity $u$ against magnitude of the tensile deviatoric stress, $-\sigma_{y}^{\prime}$. The schematic curves represent Equations (14) and (16), as indicated. For Equation (14), a stress magnitude higher than those on the curve will allow crack opening faster than freezing, as indicated by the hachures rising to the right of the curve. For Equation (16), a stress magnitude higher than those on the curve allows the crack to be wide enough, hence the water inflow to be sufficient, to maintain a water-filled crack. (One can also view these as Equation (14) requiring high velocity so that opening exceeds freezing closed, and Equation (16) requiring low velocity so that water inflow can keep up with opening.) The intersection of Equations (14) and (16) to eliminate $u$ and solving for $-\sigma_{y}^{\prime}$ yields the minimum stress magnitude allowing crack propagation, $-\sigma_{y_{-} \min }$, as indicated.

however, is expected. That is, a sufficiently deep and fully water-filled fracture will propagate easily to the base of the glacier under minimal deviatoric tensile stress and eventually even under compressive deviatoric stress. A completely water-filled crevasse $\approx 30 \mathrm{~m}$ deep has pressure inside from the excess density of water over ice sufficient to generate a stress intensity at the crack tip equal to the fracture toughness of the ice; deeper water-filled crevasses can propagate through temperate ice (Van der Veen, 1998b). In cold ice, a stronger constraint exists because the propagation must be fast enough to allow the inlet to open rapidly enough to bring in enough water to keep the crack filled and to offset the tendency to freeze. Nonetheless, if the crack is water-filled and substantially deep, the pressure of the water in a filled crack is sufficiently high that the elastic resistance of the crack walls to deformation becomes small, and the crack can propagate farther (Lister, 1990; Rubin, 1995).

For cracks that have penetrated only a short distance, however, propagation is much more difficult. The width of a crack allowing water inflow is initially small, the freezing rate in cold ice is initially large, and water inflow is insufficient to balance the freezing unless a large tensile stress is applied to open the crack quickly and allow faster water inflow.

Our numerical estimates of the required deviatoric tensile stress, 3 bar for a $1 \mathrm{~m}$ deep crack and 1.4 bar for a $10 \mathrm{~m}$ deep crack, may not seem especially high since they fall within the range of deviatoric stresses commonly observed in ice 
sheets. However, we have made several approximations that serve to greatly overestimate the ability of cracks to propagate, and thus to underestimate the deviatoric stress required for crack opening. Two of these assumptions are especially important. First, we took the potential drop driving water inflow to be linear along the crack, whereas it will be concentrated almost entirely in the crack tip (which is why we did not allow this potential drop to reduce the crack-opening stress except in considering the crack-tip stresses). Second, we did not allow freezing in the crack to restrict water inflow.

In the case of the potential gradient driving water inflow from some assumed unpressurized reservoir at the elevation of the crack top (say, a shallow stream flowing into the crack at the ice surface), we can make a crude estimate of the magnitude of the error. Rubin (1995) suggested that under a constant inflow of water to a crack deepening at constant velocity, the potential gradient should vary inversely with the flow velocity (from a flow velocity calculated following our Equation (12) assuming laminar flow between parallel plates), hence with the inverse of the square of the crack width. Elliptical cracks are often assumed, but this reduces the crack width to zero at the crack tip and creates a singularity in the calculations. To avoid this, we note that a process zone of a few millimeters to a centimeter or so is suggested by observations of healed fractures in an ice core from Kamb Ice Stream (former Ice Stream C), West Antarctica (Voigt and others, 2003), and we make the somewhat arbitrary assumption that a crack is elliptical but is truncated a few millimeters from the tip of the ellipse. Then, requiring that the average potential drop along the crack be that indicated in Equation (13) but that the local potential drop scale with the inverse of the square of the crack thickness, we find that most of the potential drop is in the crack-tip region, reducing our estimate of the potential gradient driving water inflow at the surface by roughly one order of magnitude. In turn, this leads to an increase in the calculated deviatoric stress required for crack propagation of almost twofold (Equation (18)).

Then, if freezing during crack growth restricts the crack aperture twofold (an amount chosen to be illustrative of meaningful but not near-total clogging), water inflow will be reduced eightfold following Equation (12), leading to a 50\% increase in the deviatoric stress required to open a crack. Including these two effects suggests that rather high deviatoric stresses are required to propagate shallow cracks (9 bar for a $1 \mathrm{~m}$ crack and 4 bar for a $10 \mathrm{~m}$ crack). These may increase somewhat more if allowance is made for uncertainty in the fracture toughness of ice.

In assessing the ability of a crack to propagate without freezing closed, we have not included the small effect of the pressure dependence of the melting point, nor have we included the heat generation from the water flow; while both can be quite important under appropriate circumstances, neither is significant for a crack that is not able to propagate or that is just able to propagate (Rubin, 1995). We have not attempted to model late-stage thermal processes that deviate from square-root-of-time behavior, largely because numerical techniques likely are required (Rubin, 1995), but we suspect that the ultimate fate of a crack (failure or propagation) is largely determined before enough freezing has occurred to really matter.

We thus reach the usual conclusion in fracture mechanics: once a crack is large enough, it propagates easily, but a sufficiently small crack propagates with difficulty. In our case, easy propagation requires depths of order tens of meters rather than of order meters or less.

Qualitatively, this result seems to be accurate. We have observed water standing on the surface of Greenland in many places without breaking through, including in crevasses. We have observed the sides of tabular icebergs in Scoresby Sund, East Greenland, cut by numerous 'blue bands' of refrozen meltwater, with the blue bands extending some tens of meters down from the surface and then ending. We cannot of course be certain that the cracks would not have been seen to proceed deeper had the calving event cut the ice at a different place, but the common downward termination of numerous such bands is suggestive that meltwater indeed has difficulty getting out of the nearsurface zone. The observations of moulins draining the surface into cold-ice, dirty streams emerging from beneath the ice, and ice-flow speed-up immediately after onset of water drainage into moulins (Zwally and others, 2002) indicate that some cracks do reach the bed despite the documented difficulty of doing so.

One can think of many ways to overcome this difficulty of 'nucleating' a crack so that it can reach the bed. Perhaps the easiest is to suppose that multiple fracturing events affect the same plane in the ice. If a refrozen fracture were somehow weaker than surrounding ice (perhaps because of freeze concentration of impurities in the central zone suppressing refreezing there), then a subsequent fracture might follow the same course. Through more than one such event, the temperature of the ice could be raised, reducing the freezing that tends to suppress fracture propagation. We have rarely observed such multiple fracture zones in the case of basal fractures through temperate ice of Matanuska Glacier, Alaska, USA (Ensminger and others, 2001), but we suspect that often refreezing produces a material sufficiently strong that it is not easily exploited multiple times. Closely spaced crevasses also might suppress freezing by heating their neighbors.

Another way to avoid the difficulties of nucleation is to have deviatoric stresses be large enough that the critical nucleation zone occurs primarily within the few-meter-deep zone of large seasonal temperature changes, so that the crack propagates through ice warmed by summertime. However, our calculations suggest that this may require such high stresses that glacier flow usually does not generate them.

We are especially intrigued by the possible role of lakes in fracture propagation (Scambos and others, 2000; Boon and Sharp, 2003). The Greenland ice sheet has many lakes on its surface. A lake favors warmer ice in the surface layer, by preventing wintertime cooling until all the water in the lake has frozen and by reducing surface albedo, hence increasing solar warming. The water in a lake provides a reservoir that can supply the notable volume of water needed to propagate a fracture through $>1 \mathrm{~km}$ of ice, then along the bed to some drainage, and to maintain subsequent flow long enough and with enough volume to allow collapse to a tunnel/moulin (Walder, 1982). Overpressure from a lake also can drive water inflow to the fracture (Boon and Sharp, 2003); as discussed extensively by Rubin (1995), overpressure in the fluid source promotes fracture propagation. Thus, by favoring warmer ice, providing a reservoir of water, and promoting water flow both through overpressure driving fluid and through wedging open the crack to accept more 
fluid, lakes can help overcome the main impediments to moulin formation.

As noted above, a small but rapidly growing body of literature attests to the importance of lakes in propagating fractures through cold ice. Scambos and others (2000) (also see MacAyeal and others, 2003) argued from remote-sensing observations of sections of the Larsen Ice Shelf, Antarctica, before collapse events that melt-ponding is a 'robust harbinger of ice-shelf retreat', and that crevasses in a region of melt ponding will fill to the brim with water. Numerical modeling supported this hypothesis. Boon and Sharp (2003), studying the predominantly cold John Evans valley glacier on Ellesmere Island, Canada, found that water ponding to almost $7 \mathrm{~m}$ depth preceded propagation of water-filled fractures to the bed through $150 \mathrm{~m}$ of ice at roughly $-10^{\circ} \mathrm{C}$ and establishment of a drainage system. Several 'premonitory' drainage events preceded full establishment of the drainage system.

Given the many uncertainties involved in the derivations here, we expect that considerably more sophisticated analytical models or, more likely, numerical models will be required to provide quantitatively reliable results on the conditions allowing fracture propagation and moulin formation through cold ice. We hypothesize that formation of ice surface lakes is highly favorable to moulin development. We suggest that moulin development in Greenland will be found to occur slightly down-glacier of the formation of major supraglacial lakes, and that inland migration of the zone of lake formation would allow inland migration of moulin occurrence.

Lake formation might occur in many ways, including differential ablation or other effects such as sealed crevasses or ogives. We suspect that the large lakes most favorable to crevasse propagation will form where sufficient meltwater is developed and where sufficiently tensile longitudinal deviatoric stresses exist to allow generation of local surface-slope reversals in response to variations in basal resistance to ice flow; those tensile longitudinal deviatoric stresses would also be necessary to open fractures. Additional work on the spatial distribution of surface slope reversals and longitudinal stresses, and on the occurrence of moulins and lakes, seems warranted. The possible role of the Zwally and others (2002) mechanism in up-glacier propagation of meltwater access to the bed also deserves attention; the summertime speed-up of down-glacier regions will place regions just up-glacier into tension, and may be essential in opening crevasses under lakes.

\section{CONCLUSIONS}

Downward growth of a fracture through cold ice requires water inflow at a rate sufficient to fill the fracture and maintain water pressurization, and at a rate in excess of the water loss to freezing. Both are favored by large horizontal deviatoric tension, which tends to open the fracture to allow water inflow. Both are further promoted by any supraglacial lakes, which increase the fracture-opening stress and the water inflow. In addition, warmer ice is easier for a fracture to penetrate, and may be generated by near-surface seasonal variations, multiple instances of fracturing and freezing closed (Boon and Sharp, 2003), or by the thermal effects of supraglacial lakes. Growth of a sufficiently shallow fracture in sufficiently cold ice requires either very high deviatoric stresses or 'help', probably from a supraglacial lake; fractures that have propagated deep enough $(>\mathrm{O}(10$ $100 \mathrm{~m})$ ) will continue to propagate to the bed and probably along the bed if they remain water-filled. Subsequent fluid flow down such a fracture can then form a moulin through the Walder (1982) instability. We suggest that storage of water at the surface, in lakes or in extensive but shallow crevasses, is a normal prerequisite to moulin formation through cold ice.

\section{ACKNOWLEDGEMENTS}

We thank the US National Science Foundation Office of Polar Programs (grants including 9814774, 0126187 and 0229629) and the G. Comer Foundation for support, G. Comer and G. Denton for iceberg-inspired insights on fracture propagation, P. Jansson for insights on fracturedominated glacial hydrology, and an anonymous reviewer for numerous helpful suggestions.

\section{REFERENCES}

Alley, R.B. and 6 others. In press. Outburst flooding and surge initiation in response to climatic cooling: an hypothesis. Geomorphology.

Boon, S. and M. Sharp. 2003. The role of hydrologically-driven ice fracture in drainage system evolution on an Arctic glacier. Geophys. Res. Lett., 30(18), 1916. (10.1029/2003GL018034.)

Dupont, T.K. and R.B. Alley. 2005. Conditions for the reversal of ice/air surface slope on ice streams and shelves: a model study. Ann. Glaciol., $\mathbf{4 0}$ (see paper in this volume).

Ensminger, S.L., R.B. Alley, E.B. Evenson, D.E. Lawson and G.J. Larson. 2001. Basal-crevasse-fill origin of laminated debris bands at Matanuska Glacier, Alaska, U.S.A. J. Glaciol., 47(158), 412-422.

Fischer, M.P., R.B. Alley and T. Engelder. 1995. Fracture toughness of ice and firn determined from the modified ring test. J. Glaciol., 41(138), 383-394.

Fountain, A.G., R.B. Schlichting, P. Jansson and R.W. Jacobel. 2005. Observations of englacial flow passages: a fracture-dominated system. Ann. Glaciol., 40 (see paper in this volume).

Hooke, R.LeB. 1998. Principles of glacier mechanics. Upper Saddle River, NJ, Prentice Hall.

Lister, J.R. 1990. Buoyancy-driven fluid fracture: similarity solutions for the horizontal and vertical propagation of fluid-filled cracks. J. Fluid Mech., 217, 213-239.

MacAyeal, D.R., T.A. Scambos, C.L. Hulbe and M.A. Fahnestock. 2003. Catastrophic ice-shelf break-up by an ice-shelf-fragmentcapsize mechanism. J. Glaciol., 49(164), 22-36.

Parizek, B.R. and R.B. Alley. 2004. Implications of increased Greenland surface melt under global-warming scenarios: icesheet simulations. Quat. Sci. Rev., 23(9-10), 1013-1027.

Roberts, M.J., A.J. Russell, F.S. Tweed and O. Knudsen. 2000. Ice fracturing during jökulhlaups: implications for englacial floodwater routing and outlet development. Earth Surf. Process. Landforms, 25(13), 1429-1446.

Rubin, A.M. 1995. Propagation of magma filled cracks. Annu. Rev. Earth Planet. Sci., 23, 287-336.

Scambos, T.A., C. Hulbe, M. Fahnestock and J. Bohlander. 2000. The link between climate warming and break-up of ice shelves in the Antarctic Peninsula. J. Glaciol., 46(154), 516-530.

Smith, F.W., A.F. Emery and A.S. Kobayashi. 1967. Stress intensity factors for semi-circular cracks. Part 2: semi-infinite solid. J. Appl. Mech., 34, 953-959.

Van der Veen, C.J. 1998a. Fracture mechanics approach to penetration of bottom crevasses on glaciers. Cold Reg. Sci. Technol., 27(3), 213-223. 
Van der Veen, C.J. 1998b. Fracture mechanics approach to penetration of surface crevasses on glaciers. Cold Reg. Sci. Technol., 27(1), 31-47.

Voigt, D.E., R.B. Alley, S. Anandakrishnan and M.K. Spencer. 2003. Ice-core insights into the flow and shut-down of Ice Stream C, West Antarctica. Ann. Glaciol., 37, 123-128.

Walder, J.S. 1982. Stability of sheet flow of water beneath temperate glaciers and implications for glacier surging. J. Glaciol., 28(99), 273-293.
Weertman, J. 1972. General theory of water flow at the base of a glacier or ice sheet. Rev. Geophys. Space Phys., 10(1), 287-333.

Weertman, J. 1973. Can a water-filled crevasse reach the bottom surface of a glacier? International Association of Scientific Hydrology Publication 95 (Symposium at Cambridge 1969 Hydrology of Glaciers), 139-145.

Zwally, H.J., W. Abdalati, T. Herring, K. Larson, J. Saba and K. Steffen. 2002. Surface melt-induced acceleration of Greenland ice-sheet flow. Science, 297(5579), 218-222. 